\title{
A STUDY OF THE VALUE OF ICT IN IMPROVING CORPORATE PERFORMANCE: A CORPORATE COMPETITIVENESS VIEW
}

\author{
Virginia BARBA-SÁNCHEZ ${ }^{1 *}$, María José CALDERÓN-MILÁN², \\ Carlos ATIENZA-SAHUQUILLO ${ }^{1}$ \\ ${ }^{1}$ Department of Business Administration, ESII, University of Castilla-La Mancha, Albacete, \\ Paseo de los Estudiantes, s/n, 02071 Albacete, Spain \\ ${ }^{2}$ Department of Applied Economy, Faculty of Economics and Business Administration, \\ University of Castilla-La Mancha, Avenida de España s/n, 02071 Albacete, Spain
}

Received 16 July 2017; accepted 24 March 2018

\begin{abstract}
In a context of economic crisis and strong competition between companies, managing information and knowledge seem to be key to the new productive model. The aim of this paper is to analyse the impact that the intensity of a firm's adoption of information and communications technologies (ICT) and industry attractiveness has on corporate performance. A sample of 871 SMEs took part in the study and data were analysed using ordered logistic regression and principal axis factoring analysis. The results emphasise the existence of a significant positive relationship between ICT intensity of use and corporate performance and highlight the importance of ICT in very competitive environments. Our survey suggests that full integration of ICTs in the company is advisable. The drawback, however, is that the rapidly changing nature of ICTs makes the adoption of emerging ICTs difficult.
\end{abstract}

Keywords: Information and communications technologies (ICT), corporate performance, sustaining ICT advantage, Porter's Competitive-Forces Framework, ICT intensity, industry attractiveness.

JEL Classification: L25, M15, O33, C31, C38.

\section{Introduction}

The current economic environment is extremely turbulent and this is mainly due to rapid technological change and the increase in competition between companies. In such a context, a company's survival depends on its ability to successfully adapt its strategies in response to the changing environment.

The information society and knowledge economy has resulted in the transformation of the economy, contributing to globalisation and encouraging intangible economic activity

*Corresponding author. E-mail: virginia.barba@uclm.es

This is an Open Access article distributed under the terms of the Creative Commons Attribution License (http://creativecommons. $\mathrm{org} / \mathrm{licenses} / \mathrm{by} / 4.0 /$ ), which permits unrestricted use, distribution, and reproduction in any medium, provided the original author and source are credited. 
(Avgerou, 2010). Companies consequently face a relentless increase in global competition whereby they are forced to adapt to their constantly changing surroundings and to new changes in demand. It is therefore essential that companies respond quickly and innovatively and this will in turn increase their overall efficiency and effectiveness (Berraies \& Chaher, 2014).

In this context, companies must develop new strategies in order to adapt to this global environment and guarantee their long-term survival. According to Venturi (2015), the adoption of information technologies leads directly to efficiency and competitiveness, and indirectly according to Torrent-Sellens and Díaz-Chao (2014) to the generation of complementary innovations that improve productivity. The idea is that greater productivity results in better performance and a better competitive position of the company in the market, which implies that information and communications technologies (ICTs) can be a source of competitive advantage (Pavic, Koh, Simpson, \& Padmore, 2007). Despite Ulmanis and Deniṇš (2012) stating that while no significant changes had been reported in ICT use by Latvian firms in the time period 2008-2011, they had observed that the large number of ICT users in general did receive greater increased opportunities from ICTs for facing up to financial crisis challenges. Regarding the Spanish economy, while the results obtained by Badescua and Garcés-Ayerbe (2009) show that this improvement in labour productivity was not significantly generated by IT investment; López Sánchez, Minguela, Rodríguez, and Sandulli (2006) found a positive impact on labour productivity from IT investments and Internet use. The link between ICT intensity of use and corporate performance is complex and from an empirical point of view, the corporate performance impact of ICT intensity of use is difficult to estimate (Pantea, Sabadash, \& Biagi, 2017): due to their multifaceted and intangible nature, technological change in general, and diffusion in particular, are difficult to capture in data.

According to Drew (2003), the impact of ICTS is more apparent in industries with a strong competitive advantage than in those with greater entry barriers such as construction and heavy industries, where the impact tends to be more gradual. Research conducted by Pontikakis, Lin, and Demirbas (2006) into IT adoption in Greek small and medium-sized enterprises (SMEs) suggests that highly competitive industries are often more technologically intensive. The reason for this is that SMEs involved in highly competitive industries tend to adopt a higher number of more sophisticated ICT solutions in order to be more efficient both on an internal and external level. Pantea et al. (2017) concludes, however, that empirical evidence on the effect of ICT at firm level is mixed and inconclusive and therefore, future work should address this topic more directly.

In this paper, we address the existing gap in the empirical literature by exploiting micro-data that relates ICT variables to indicators of industry's level of competitive intensity. On the basis of Porter's holistic five competitive forces model (1998), a management tool to externally analyse the companies created and that compete in a certain sector, the main aim of this article is to examine the impact that ICT intensity of use and sector attractiveness has on corporate performance. The paper makes three mayor contributions to the literature. First, it is one of the few studies that have used diversity of corporate performance measures regarding ICT use. S second, the paper focuses explicitly on the industry's level of competitive intensity effect, which is highly policy relevant in the short to medium term and in periods 
characterised by low economic growth. Finally, this investigation provides empirical evidence in the Spanish context about the effect of ICTs on corporate performance.

The article is organised as follows: Section 1 reviews literature on ICT adoption and the derived various benefits for organisations; Section 2 describes and analyses the sample studied and the methods used; Sections 3 analyses the results; and finally, Conclusion section outlines our main conclusions and the possible implications of the results obtained in this research work.

\section{Theoretical framework}

The combined result of globalisation and the economic crisis has necessitated a change in the productive model where the greatest added value products and services are developed. Correspondingly, both economies and companies are evolving towards models in which the importance of industrial processes is replaced by the relevance of information and knowledge management as economic keys (Stirbu, Ceptureanu, \& Ceptureanu, 2015), configuring the so-called knowledge economy (Marrano, Haskel, \& Wallis, 2009). One of the features of this new economy is the increase in corporate investment in new information and communications technologies. Various authors have highlighted the role played by these technologies in facilitating knowledge creation and dissemination (Wai-Sum \& Bao, 2008), reducing the transaction costs between activities (Malone, Yates, \& Benjamin, 1987), decreasing the risk inherent to each transaction and improving the efficiency of value chain activities (BarbaSánchez, Martínez-Ruíz, \& Jiménez-Zarco, 2007). However, the analyses undertaken in different geographical areas regarding their impact on corporate performance and competitiveness have not lead to entirely unequivocal conclusions (Benito-Hernández, Platero-Jaime, \& Rodríguez-Duarte, 2012). The aim of this work is therefore to transfer this debate to Spain in order to estimate the impact that ICT introduction is having on corporate competitiveness and performance.

According to various authors (e.g. Andersen, 2015 or Cohen \& Olsen, 2015), ICTs play a decisive role since they represent a source of competitive advantages stemming from differentiation, better service or lower costs. Not only do ICTs facilitate corporate activities, the use of intangibles and the spillover effects of technology and knowledge, but they are fundamental for the adoption of new networked organisational practices, they facilitate human capital training and the development of new labour policies, and they enable cooperation with external company experts (Venturi, 2015). ICTs represent the basic structure of the global knowledge economy and since they are, according to Bresnahan and Trajtenberg (1995), general purpose technologies, they contribute both directly (Venturi, 2015) and indirectly to improving the corporate result (Torrent-Sellens \& Díaz-Chao, 2014). According to Mačiulytė-Šniukienè and Gaile-Sarkane (2014), the direct effect is due to the improvement of internal and external corporate processes which reduces business costs and to the greater efficiency of distribution mechanisms for marketplace transactions, and this in turn affects economic growth. Accordingly, Harris (2016) even considers information and communications technologies for development (ICT4D). It is also necessary to highlight the role of ICTs as facilitators in coordinating and managing business operations, thereby enabling more 
efficient decision-making (Brynjolfsson \& Hitt, 2000). The indirect effect stems from the installation of innovative elements, which enable for example differentiation from competition by creating a new, more credible image (Mehrtens, Cragg, \& Mills, 2001) in order to attract new clients and increase company income.

Furthermore, Morikawa (2004) presents empirical evidence to suggest that those companies with a greater ICT intensity of use are more likely to engage in R\&D activities and thereby obtain better results in line with the conclusions obtained by Mercader, Merono, and Sabater (2006). The authors Bayo-Morionesa, Billon, and Lera-López (2013) also point out that although ICTs have a significant impact on improving external and internal communications, they do have a limited impact on the company's overall operative result. This research shows the direct effect that ICTs have on corporate performance.

Certain researchers such as Roach (1991) or Carr (2003), however, question the existence of a positive relationship between ICTs and the corporate result especially in the short term. In this respect, Brynjolfsson and Hitt (2000) indicate that the advantages of ICT implementation in a company are not immediately apparent but require a period of technological adaptation during which it is advisable to train workers, modify work methods and even organizationally restructure the company for the results of ICT adoption to be positive.

For Carr (2003), meanwhile, the adoption of a large number of ICT products and services has meant that these have become commodities which no longer provide strategic competitive advantages for the company even though they are still indispensable for operation. Growing user interest in common standardised tool packages and the progressive decrease in product and support prices have encouraged the use of certain ICT services. However, according to Niemi (2006), even in these cases ICTs continue to be a source of strategic advantage due to the integration of such technologies in company structure and management, as coined by the phrase enterprise architecture ${ }^{1}$. Rohrbeck (2010) also studied the effects of ICTs on sustainable, competitive advantages and also concluded that not only do ICTs generate advantages but they also produce positive synergies as a result of their integration with other corporate activities and the dynamics of the economic and social environment. According to Tvrdíkováa (2016), what is important for obtaining competitive advantages as a result of ICTs is information and cooperation with other sector agents, whether these be suppliers, clients or partners. Technology is essential so that this information may be updated, contrasted and managed quickly and efficiently and so that better decisions can be made. As Gonzálvez-Gallego, Molina-Castillo, Soto-Acosta, Varajaoc, and Trigod (2015) suggest, when used correctly, it also enables the inefficiencies arising from sharing corporate data to be eliminated with an immediate impact on corporate performance.

In this respect, Platero-Jaime, Benito-Hernández, and Rodríguez-Duarte (2017) believe that companies must modify their corporate structure in order to adapt to the local network configuration of these technologies and to operate in an interconnected way by linking ICTs with business process reengineering (BPR). This would in turn enable an in-depth analysis and redesign of anything related to a certain business area so that improvements could be

\footnotetext{
${ }^{1}$ An enterprise architecture describes the structure of a company with its components and the connections between these, defining the principles and rules for the design and operability of the organisational structure, the information processes and systems of the company, and synchronising ICTs with corporate processes and goals (Dankova, 2009).
} 
made and the associated change process managed. The flexibility of the new structure enables the company to immediately respond to the new consumption patterns which increasingly require more knowledge-intensive goods and services (Berraies \& Chaher, 2014).

According to Harris (2016), there is a certain degree of consensus in literature about the relationship between the inclusion of ICTs in companies and how useful they are considered to be. Authors such as Burke (2010) or Dholakia and Kshetri (2004) indicate that the perceived benefits brought by ICTs to companies are decisive for their adoption from a proactive perception. In this respect, when companies invest in ICTs one of their aims (Barba-Sánchez et al. 2007) is to differentiate themselves from their competitors, take advantage of new business opportunities, reduce costs or increase income, and this will affect to a greater or lesser extent productivity (Arvanitis \& Loukis, 2009) and eventually global performance and profitability (Benitez-Amado \& Walczuch, 2012). Other authors such as Ghobakhloo, Sabouri, Hong, and Zulkifli (2011) or Nguyen (2009), however, argue that companies have had no choice but to incorporate ICTs in response to internal and external pressure from either their clients or competitors, contributing to their survival but not to their growth from a reactive perspective. By considering these premises it is possible to advance the following hypothesis that refers to the impact of the intensity of ICT usage on the corporate result:

Hypothesis 1. The different dimensions of ICT intensity of use (ICTIU) have a direct positive effect on the entrepreneur's perceived usefulness of ICT in terms of improving corporate performance.

Most empirical research specialising in ICTs uses a global indicator to measure the corporate performance and this presupposes that if this indicator improves then the other performance measures will automatically increase. However, in view of the vast variety and diversity of corporate performance measures that exist, Xue, Ray, and Sambamurthy (2012) suggest that certain corporate ICTs could in fact contribute to improving efficiency or increasing innovation in terms of the industry or corporate strategy. Ca'Zorzi (2011), on the other hand, indicates that the use of ICTs positively contributes to higher income for smalland medium-sized enterprises (SMEs). We therefore consider it appropriate to split this first hypothesis into the following subhypotheses:

Hypothesis 1a. The different dimensions of ICT intensity of use (ICTIU) directly and positively affect the entrepreneurs' perceived usefulness of ICT in terms of competitiveness.

Hypothesis 1b. The different dimensions of ICT intensity of use (ICTIU) have a direct positive effect on the entrepreneurs' perceived usefulness of ICT in terms of reducing business costs.

Hypothesis 1c. The different dimensions of ICT intensity of use (ICTIU) directly and positively affect the entrepreneurs' perceived usefulness of ICT in terms of taking advantage of business opportunities.

Hypothesis 1d. The different dimensions of ICT intensity of use (ICTIU) directly and positively affect the entrepreneurs' perceived usefulness of ICT in terms of increasing income.

Hypothesis 1e. The different dimensions of ICT intensity of use (ICTIU) directly and positively affect the entrepreneurs' perceived usefulness of ICT in terms of improving corporate productivity. 
Hypothesis 1f. The different dimensions of ICT intensity of use (ICTIU) directly and positively affect the entrepreneurs' perceived usefulness of ICT in terms of improving overall corporate performance.

Porter and Millar (1985) stated that this strategic ICT role does not have the same importance in every company since the nature of competition and industrial structure can change as a result of IT adoption. In fact, the structure-conduct-performance paradigm defended for example by Schmalensee (1989) or Porter (1998) suggests that the structure of an industry -what Porter (1980) calls their attraction- affects how companies behave and perform in this sector. According to Dalken (2014), Michael Porter's model of the five forces of competition remains valid in digital environments for viewing industry competition and attractiveness. In this respect, Dewett and Jones (2001) confirm an important link between investment and ICT use and the improvements in corporate competitiveness, both from the perspective of reducing costs and from the perspective of broadening or diversifying products and markets. Burke (2010), on the other hand, analyses the impact of an industry's development phase on ICT intensity of use and reaches the conclusion that the characteristics of the industrial sector in which a firm competes affects that firm's ICT intensity of use. Additionally, Xue et al. (2012) maintain that the nature of the industry in which a company competes will have a significant moderating effect on the relationship between the company's ICT asset portfolio and its performance in terms of company efficiency and innovation.

In the Spanish context, Delgado-Gómez, Ramírez, and Espitia (2004) or Pla-Barber (2000) have verified the positive relationship between technological and organizational innovation and also that of other intangible assets, and the international competiveness of their industrial companies. In line with more recent research (e.g. Strobel, 2014; Díaz-Chao, Sainz-González, \& Torrent-Sellens, 2015), the adoption and intensive use of information technologies entails the need for the availability of better trained workers who in turn can use far more sophisticated technology which will lead to an increase in productivity and corporate competitiveness. In this virtuous circle between technology and human capital, the companies and countries who invest most in training will be most successful.

By considering these premises, it is possible to advance the following hypothesis that refers to the impact of industry attractiveness on perceived corporate performance:

Hypothesis 2. The greater the entrepreneur's perception of industry attractiveness (IA), the greater the perceived usefulness of ICT in terms of improving corporate performance. In accordance with the first hypothesis and given the breadth of the endogenous variable, we consider it appropriate to split this hypothesis into the following subhypotheses:

Hypothesis 2a. The greater the entrepreneur's perception of industry attractiveness (IA), the greater the perceived usefulness of ICT (PUICT) in terms of competiveness.

Hypothesis 2b. The greater the entrepreneur's perception of industry attractiveness (IA), the greater the perceived usefulness of ICT (PUICT) in terms of reducing business costs.

Hypothesis 2c. The greater the entrepreneur's perception of industry attractiveness (IA), the greater the perceived usefulness of ICT (PUICT) in terms of taking advantage of business opportunities. 
Hypothesis 2d. The greater the entrepreneur's perception of industry attractiveness (IA), the greater the perceived usefulness of ICT (PUICT) in terms of increasing income.

Hypothesis 2e. The greater the entrepreneur's perception of industry attractiveness (IA), the greater the perceived usefulness of ICT (PUICT) in terms of corporate productivity.

Hypothesis 2f. The greater the entrepreneur's perception of industry attractiveness (IA), the greater the perceived usefulness of ICT (PUICT) in terms of overall corporate performance.

\section{Materials and methods}

\subsection{Data collection and sample}

This research examines improvements in corporate performance due to ICT intensity of use in sectors with different levels of attractiveness by analysing data from a survey conducted with a representative sample (joint margin of error of $+/-3.3 \%$ in the case of maximum indetermination, $\mathrm{p}=\mathrm{q}=50$, and a level of confidence of 95\%) of 871 firms out of 3,186,878 which are listed in the INE's Central Company Directory (DIRCE) (INE, 2015). The sample provided good representation of companies of different sizes (measured by total of number of employees (see Table 1), which really no differ greatly from each other in regard to the population size distribution (see Table 1). Despite the sample tended towards micro-enterprises with more than 80\% of the companies having less than 10 employees, according to the definition of European Commission (2014), firms size in our sample tend to be larger than those in the target population. Perhaps it was the result of the possible poor response rate of the smallest enterprises. In addition, regardless of the origin of their capital or the location of their headquarters, these companies developed their activity in Spain.

Table 1. Size of firms (source: own compilation and INE (2015))

\begin{tabular}{|c|c|c|c|c|}
\hline \multirow{2}{*}{ Number of employees } & \multicolumn{2}{|c|}{ Sample } & \multicolumn{2}{|c|}{ Population (DIRCE) } \\
\hline & Count & Percent & Count & Percent \\
\hline Without employees & 439 & 0.50402 & $1,754,002$ & 0.55038 \\
\hline $1-2$ & 195 & 0.22388 & 899,802 & 0.28235 \\
\hline $3-5$ & 67 & 0.07692 & 287,430 & 0.09019 \\
\hline $6-9$ & 28 & 0.03215 & 112,527 & 0.03531 \\
\hline $10-19$ & 28 & 0.03215 & 71,518 & 0.02244 \\
\hline $20-49$ & 19 & 0.02181 & 39,101 & 0.01227 \\
\hline $50-99$ & 46 & 0.05281 & 11,503 & 0.00361 \\
\hline $100-199$ & 23 & 0.02641 & 5,928 & 0.00186 \\
\hline $200-499$ & 19 & 0.02181 & 3,340 & 0.00105 \\
\hline $500-999$ & 4 & 0.00459 & 937 & 0.00029 \\
\hline $1,000-4,999$ & 2 & 0.00230 & 683 & 0.00021 \\
\hline$\geq 5,000$ employees & 1 & 0.00115 & 107 & 0.00003 \\
\hline Total & 871 & 1.00000 & $3,186,878$ & 1.00000 \\
\hline
\end{tabular}


The information was gathered by means of a self-administered questionnaire which was sent to company managers and personal interviews which were conducted during the month of January 2016. Given the poor response, a second round was necessary during the month of March. In terms of the non-response bias, late respondents are presumed to exhibit similar characteristics to non-respondents following Assael and Keon's (1982) recommendations. Of all the variables considered, there are no significant differences between the two groups when the $\mathrm{t}$ - and Chi-squared tests are used (using the single-tail t-tests at the 0.05 significance level). Item non-response is another problem that frequently occurs in survey data. The normal procedure is to omit any observations with incomplete data and so the final total of valid surveys was 776 . The high number of invalid questionnaires was mainly due to the inexperience of the interviewers although with this type of personal interview we managed to increase the response rate that would have been obtained for example with a postal survey. More specifically, $60 \%$ of the companies contacted eventually completed the survey.

\subsection{Measures}

We shall now discuss each of our analysis variables. The dependent variables are those relating to corporate performance and were measured by following the approaches of Covin, Prescott, and Slevin (1990) or Senarathne-Tennakoon, da Silveira, and Taras (2013) by means of interviewee perceptions. As companies are extremely reluctant to provide quantitative data of an economic or financial nature, higher response indexes are obtained if self-appraisals of performance are requested. Additionally, according to Fisher (1992), non-financial performance measures, which include entrepreneur perceptions, are valid for analysing the impact of multidimensional factors with indirect effects, as in the case of ICTs.

More specifically, on the basis of reference works (e.g. Hollenstein, 2004; Ca'Zorzi, 2011), people were asked about the actual benefits derived from ICT adoption using Likert-type 5 -point questions. Managers had to state how far they agreed or disagreed with a series of statements relating to whether ICTs had helped their company improve in terms of their competitiveness (Liu \& Ravichandran, 2008), reducing business costs (Xue et al., 2012), taking advantage of business opportunities (Ravichandran, 2005), of productivity (Harindranath, Dyerson, \& Barnes, 2008), of income (Ca'Zorzi, 2011) or overall corporate performance, where 1 represents "strongly disagree" and 5 "strongly agree".

There are two independent or explanatory variables: ICT intensity of use and industry attractiveness. Firstly, the questions relating to current ICT intensity of use focused on the types of ICT used (e.g. email, Internet, WIFI, etc.) and kinds of ICT applications (stock control, sales, marketing, human resource management, enterprise resource planning, etc.) were answered with either a 'yes' or 'no' in accordance with specialist literature (e.g. Molla \& Licker, 2005; Burke, 2010). Secondly, industry attractiveness was measured using the most well-known industry-structure model: Porter's (1980) competitive-strategy model. Authors as Dalken (2014) or Ho (2016) consider that this model is still a powerful management tool for analysing current industry profitability and attractiveness. According to Spanos and Lioukas (2001), competitive forces (the threat of new entrants, the threat of substitute products, the intensity of rivalry among competitors, the bargaining power of buyers, and the bargaining 
power of suppliers) were all measured by single items. Using Likert-type 5-point questions, managers had to assess the rivalry existing between firms, with 1 for "very low" and 5 "very high"; how easy it is for new firms to enter and compete in this industry, where 1 is "very easy to enter" and 5 "very difficult to enter"; to what degree this industry is threatened by substitute products/services, with 1 for a "very low threat" and 5 "very high threat"; what level of bargaining power suppliers and buyers have, with 1 being "very weak power" and 5 "very strong power". The collective strength of these forces determines the degree of competition and the ultimate profit potential in the industry (Ho, 2016) and, for each respondent, we have computed it as the sum of these five forces, as in Marx (2017). Appendix 1 shows the means and standard deviations of the research variables.

\subsection{Method}

Given that the variables that we want to model are categorical variables for which order is an important factor (they are measured on the Likert 5 scale) we shall use ordered logistic regression (often just called "ordered regression"). The ordered logit model is a regression model for ordinal dependent variables.

An ordered logistic regression model for a single independent variable would have the following specification (1):

$$
\ln \left(\theta_{j}\right)=\alpha_{j}-\beta X
$$

where $\mathrm{j}$ would take values from 1 to one less than the number of categories.

Each logit has its own constant $\left(\alpha_{j}\right)$ but the same gradient $(\beta)$. This means that the effect of the independent variable is the same for the different logit functions. This supposition must be contrasted and is called a parallel line test.

These ordinal regression models are an extension of the binary logistic regression model where the dependent variable would take more than two possible values (polytomous models). The dependent variable also tends to follow an order of precedence between the different categories, but the real distance between them is unknown.

In turn, these models are a generalization of the classic linear regression model for ordinal categorical dependent variables. Like classic regression models, they enable the inclusion of categorical and continuous independent variables, with the added advantage of not requiring suppositions such as normality, homoscedasticity or residual intercorrelation. The ordinal regression model does, however, suppose one condition on data to be modelled: proportional odds or parallel lines. The null hypothesis of this test indicates the proportional odds assumption. If the proportional odds assumption was violated, we may want to go with multinomial logistic regression. During model validation and selection, we shall check not only $\mathrm{H}_{0}$ compliance in the parallel line test but we shall also evaluate the statistical significance of each of the parameters estimated in the model (using the Wald test) and taking into account the goodness of fit of the different estimated models.

One of the decisions that must be made when considering logistic regression model is the choice of link function (Norusis, 2005). The logit function is the most common and this would be selected once the categories of the dependent variable had been distributed. If the higher categories were most probable, the complementary log-log function would be cho- 
sen, and if the lower categories were most probable, the negative log-log would be chosen, among others.

According to Hair, Anderson, Tatham, and Black (1998), multivariate regression models are the most suitable method for studies where there are no variables which act either dependently or independently at the same time, in which case structural equation analysis would be used. The Structural Equation Modelling (SEM) techniques are used to accommodate that include reciprocal causation, simultaneity and interdependence relationships. This is not our case, we have just one dependent variable, the perceived usefulness of ICTs, then we have choose a regression model with one-equation.

The logit ordered models coefficients differ by a scale factor and therefore we cannot interpret the magnitude directly. Then, we estimate the marginal effects.

The marginal effects show the change in probability when the independent variable increases by one unit. For ordered logistic models, the change in probability for each factor level depends on the discrete change from the base level. We calculate so much marginal effects as categories for dependent variable.

The marginal effects are calculated as:

$$
\partial p\left(y_{i}=j\right) / \partial x_{i m}=\left[F^{\prime}\left(\alpha_{j-1}-\beta^{\prime} X_{i}\right)-F^{\prime}\left(\alpha_{j}-\beta^{\prime} X_{i}\right)\right]^{\star} \beta_{m},
$$

where $j$ would take values from 1 to number of categories; $x_{m}$ is each independent variable and $\beta_{m}$ is its coefficient. $F^{\prime}$ is the derivated function.

\section{Results}

In order to reduce the number of survey variables that represent ICT intensity of use, we conducted a principal axis factoring analysis (PCA) of the indicators used for the three constructs. In turn, this technique enables us to avoid the problem of multicollinearity among explanatory variables when we estimate econometric models since it confirms the independence of the new variables or factors created.

In order to guarantee the adequacy of our sample for this principal axis factoring method, the statistics shown in Table 2 were calculated. This reveals how our sample suits this type of factorial analysis given that a KMO statistic close to one was obtained. More specifically, this indicates the proportion of variance shared by the variables included in our analysis (91.5\%). Bartlett's test of sphericity also enables us to reject the null hypothesis that the correlation matrix is an identity matrix.

Table 2. Sampling adequacy statistics for main component analysis: KMO and Bartlett's test

\begin{tabular}{|c|c|c|c|}
\hline \multirow{2}{*}{$\begin{array}{c}\text { Kaiser-Meyer-Olkin } \\
\text { Measure }\end{array}$} & \multicolumn{3}{|c|}{ Bartlett's test of sphericity } \\
\cline { 2 - 4 } & Approx. Chi-square & $\mathrm{df}$ & Sig. \\
\hline 0.915 & 3997.2 & 153 & 0.000 \\
\hline
\end{tabular}

We begin with 18 items which measure the variable ICT intensity of use in the SME. As Table 3 shows, this set of items is reduced to 3 dimensions or factors which explain $70.79 \%$ 
of the total variance (following the Kaiser criterion we have considered the principal components with values greater than one). In order to facilitate interpretation of these three factors, Table 3 shows the rotated factor matrix with the Varimax Method. The rotated factors ensure that each of the original variables has the closest possible correlation to one with some of the factors. Given the factor loadings, we have considered the following interpretation of factors:

- Factor 1: basic ICT elements. The highest factorial loads correspond to Internet connection, basic computer equipment, office and security applications, local networks and WIFI connection, and mobile devices.

- Factor 2: management elements. This component would mainly comprise storage management software, invoicing, accountancy and backup and video surveillance systems.

- Factor 3: Advanced ICT elements and logistics. This component would comprise more sophisticated equipment, software and management elements such as QR codes, RFID labels, geolocation and integral management systems, among others.

In order to contrast the work hypothesis that relates each of the ICT intensity and industry attractiveness factors with the perceived usefulness of ICTs in terms of improving corporate performance, the ordinal regression model was used to estimate the models shown in Table 4.

Table 3. Principal axis factoring: rotated factor matrix ${ }^{\mathrm{a}}$ (source: own compilation)

\begin{tabular}{|l|c|c|c|}
\hline \multirow{2}{*}{} & \multicolumn{2}{|c|}{ Factor } \\
\cline { 2 - 4 } & 1 & 2 & 3 \\
\hline 1. Computer equipment (printer, PC, laptop) & 0.706 & & \\
\hline 2. Mobile devices (PDA, Smartphones, TabletPC) & 0.474 & & 0.352 \\
\hline 3. Backup systems & 0.424 & 0.473 & \\
\hline 4. Video surveillance cameras & & 0.517 & \\
\hline 5. Local networks, WIFI connection & 0.586 & & \\
\hline 6. TPVs, touchscreens & & & 0.499 \\
\hline 7. Geolocation systems & & & 0.608 \\
\hline 8. QR code & & & 0.633 \\
\hline 9. RFID labels & & & 0.596 \\
\hline 10. Office applications & 0.683 & 0.333 & \\
\hline 11. Accountancy applications & 0.449 & 0.623 & \\
\hline 12. Computerised invoicing management & 0.362 & 0.715 & \\
\hline 13. Computerised warehouse management & & 0.726 & \\
\hline 14. Integral management systems (ERP, CRM) & & 0.374 & 0.566 \\
\hline 15. Security applications (antivirus, firewall) & 0.676 & 0.302 & \\
\hline 16. Use of free software & 0.389 & & 0.470 \\
\hline 17. Webpage & 0.395 & & 0.435 \\
\hline 18. Internet connection & 0.770 & & \\
\hline
\end{tabular}

Notes: Extraction method: Principal Axis Factoring: Rotation Method: Varimax with Kaiser Normali-

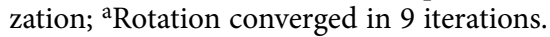


Table 4. Ordered logistic regressions (source: own compilation)

HYPOTHESIS 1: PUICT $=\mathrm{f}($ IUTIC $)$; HYPOTHESIS 2: PUICT $=\mathrm{f}($ IA $)$

\begin{tabular}{|c|c|c|c|c|c|c|c|}
\hline & \multicolumn{6}{|c|}{ Dependence Variable: Thanks to ICTs, the company has: } \\
\hline & & 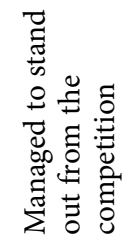 & 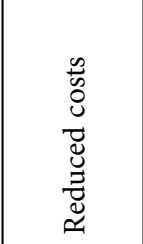 & 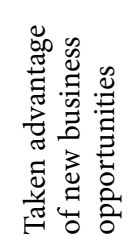 & 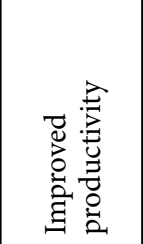 & 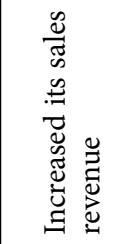 & 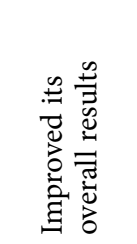 \\
\hline \multirow{4}{*}{ Threshold } & {$[$ PUICT $=1]$} & $-0.986^{\star \star *}$ & $-10.309^{\star \star \star}$ & $-10.274^{\star * \star}$ & $-10.663^{\star * *}$ & $-10.353^{\star \star \star}$ & $-10.778^{\star * \star}$ \\
\hline & {$[\mathrm{PUICT}=2]$} & 0.522 & 0.204 & 0.191 & -0.133 & 0.356 & -0.128 \\
\hline & {$[\mathrm{PUICT}=3]$} & $20.155^{\star * *}$ & $10.934^{\star * \star}$ & $10.762^{\star * *}$ & $10.489^{\star * *}$ & $10.939^{* * *}$ & $10.589^{* * *}$ \\
\hline & {$[\mathrm{PUICT}=4]$} & $30.862^{* * *}$ & $30.649^{\star * \star}$ & $30.416^{\star * *}$ & $30.281^{* * *}$ & $30.771^{\star * *}$ & $30.448^{\star * *}$ \\
\hline \multirow{4}{*}{ Location } & IA & $0.067^{\star * *}$ & $0.052^{* *}$ & $0.067^{\star * \star}$ & $0.044^{\star *}$ & $0.061^{\star * *}$ & $0.053^{\star *}$ \\
\hline & IUTIC_basic & $0.681^{* * *}$ & $0.790^{* * *}$ & $0.817^{\star * *}$ & $0.770^{* * *}$ & $0.684^{\star * *}$ & $0.759^{* * *}$ \\
\hline & IUTIC_management & $0.410^{* * *}$ & $0.544^{\star * \star}$ & $0.493^{\star \star \star}$ & $0.502^{\star * *}$ & $0.503^{\star * *}$ & $0.537^{\star * \star}$ \\
\hline & IUTIC_advanced & $0.569^{\star * *}$ & $0.443^{* * *}$ & $0.638^{\star * *}$ & $0.461^{\star * *}$ & $0.490^{* * *}$ & $0.518^{\star * *}$ \\
\hline \multicolumn{2}{|c|}{$\begin{array}{l}(1) \text { Model fitting information } \\
\left(\chi^{2}{ }_{4}\right)\end{array}$} & 186.66 & 209.83 & 239.32 & 194.86 & 183.36 & 206.61 \\
\hline \multicolumn{2}{|c|}{ Pseudo- $\mathrm{R}^{2}$ Nagelkerke } & 0.238 & 0.263 & 0.293 & 0.247 & 0.234 & 0.260 \\
\hline \multicolumn{2}{|c|}{ (2) Parallel line test $\left(\chi^{2}{ }_{12}\right)$} & 13.89 & 12.31 & 12.94 & 20.56 & 26.38 & 23.51 \\
\hline
\end{tabular}

Notes: Link function: Logit. Software: SPSS $22 ;{ }^{* *}$ p-value $<0.01 ;{ }^{* *} \mathrm{p}$-value $<0.05{ }^{*}$ p-value $<0.1$;

(1) The null hypothesis of this test is that the model is adequate without the inclusion of the explanatory variables. Value tables $\chi^{2}{ }_{4}=9.49$ (significant level 0.05 ). We hope to reject $\mathrm{H}_{0}$;

(2) The null hypothesis of this test is that there is no difference in the coefficients between models, so we hope to obtain a non-significant result. Value tables $\chi^{2}{ }_{12}=21.02$ (significant level 0.05).

In terms of Hypothesis 1, it is clear that the coefficients estimated in the different models are all significant and this shows that an increase in ICT intensity increases the perceived probability that thanks to ICTs a company is able to stand out from its competitors, reduce costs, take advantage of new business opportunities, increase productivity and income, and generally improve its overall performance. In the same way, Hypothesis 2 is also confirmed, since greater industry attractiveness increases the perceived probability that thanks to ICTs the company is able to stand out its competitors, reduce costs, take advantage of new business opportunities, increase productivity and income, and generally improve its overall performance.

The goodness of fit tests are adequate for all of the estimated models. The levels obtained by the pseudo-R2 are acceptable. The parallel line tests indicate that in Models 1, 2, 3 and 4 the ordinal logistic modelling is adequate, given that the gradients for all the factors that measure ICT intensity of use are the same for all the response categories. The same cannot be said for Models 5 and 6, where the parallel line test rejects gradient equality which means that the effect of ICT intensity of use on corporate performance will vary according to response category. 
In addition, the marginal effects are calculated on the basis of the estimations in Table 4 to measure the change in probability for each category of dependent variable (see Table 5). To interpret the results, the marginal effects for dependent variable in Model 1 show, for example, how much will increase the probability that manager strongly agree that thanks to ICT the company has managed to stand out from the competition. Therefore, one unit increase in IA is associated with being $0.7 \%$ less likely to be in strongly disagree, $0.9 \%$ less likely to be in disagree, $0.3 \%$ more likely to be neither agree nor disagree, $0.9 \%$ more likely to be in agree and $0.4 \%$ more likely to be in strongly agree, that thanks to ICT the company has managed to stand out from the competition.

Table 5. Marginal effects for ordered logistic regressions (source: own compilation)

\begin{tabular}{|c|c|c|c|c|c|c|}
\hline $\begin{array}{l}\text { Thanks to } \\
\text { ICTs, the } \\
\text { company has: }\end{array}$ & & PUICT $=1$ & PUICT $=2$ & PUICT $=3$ & PUICT $=4$ & $\mathrm{PUICT}=5$ \\
\hline \multirow{4}{*}{$\begin{array}{l}\text { Managed to } \\
\text { stand out } \\
\text { from the } \\
\text { competition }\end{array}$} & IA & -0.0067 & -0.0089 & 0.0027 & 0.0091 & 0.0037 \\
\hline & IUTIC_basic & -0.0673 & -0.0899 & 0.0271 & 0.0922 & 0.0378 \\
\hline & IUTIC_management & -0.0405 & -0.0541 & 0.0163 & 0.0555 & 0.0228 \\
\hline & IUITC_advanced & -0.0562 & -0.0751 & 0.0226 & 0.0770 & 0.0316 \\
\hline \multirow[t]{4}{*}{ Reduced costs } & IA & -0.0048 & -0.0069 & 0.0020 & 0.0069 & 0.0028 \\
\hline & IUTIC_basic & -0.0740 & -0.1049 & 0.0307 & 0.1059 & 0.0422 \\
\hline & IUTIC_management & -0.0510 & -0.0723 & 0.0212 & 0.0730 & 0.0291 \\
\hline & UITC_advanced & -0.0415 & -0.0588 & 0.0172 & 0.0594 & 0.0237 \\
\hline \multirow{4}{*}{$\begin{array}{l}\text { Taken } \\
\text { advantage of } \\
\text { new business } \\
\text { opportunities }\end{array}$} & IA & -0.0053 & -0.0085 & -0.0012 & 0.0096 & 0.0055 \\
\hline & IUTIC_basic & -0.0641 & -0.1038 & -0.0149 & 0.1166 & 0.0663 \\
\hline & IUTIC_management & -0.0387 & -0.0626 & -0.0090 & 0.0703 & 0.0400 \\
\hline & IUITC_advanced & -0.0501 & -0.0810 & -0.0116 & 0.0910 & 0.0517 \\
\hline \multirow{4}{*}{$\begin{array}{l}\text { Improved } \\
\text { productivity }\end{array}$} & IA & -0.0034 & -0.0058 & -0.0003 & 0.0066 & 0.0029 \\
\hline & IUTIC_basic & -0.0598 & -0.1018 & -0.0044 & 0.1152 & 0.0509 \\
\hline & IUTIC_management & -0.0390 & -0.0664 & -0.0029 & 0.0751 & 0.0332 \\
\hline & IUITC_advanced & -0.0358 & -0.0610 & -0.0027 & 0.0690 & 0.0305 \\
\hline \multirow{4}{*}{$\begin{array}{l}\text { Increased its } \\
\text { sales revenue }\end{array}$} & IA & -0.0049 & -0.0089 & 0.0016 & 0.0088 & 0.0033 \\
\hline & IUTIC_basic & -0.0550 & -0.1003 & 0.0181 & 0.0998 & 0.0373 \\
\hline & IUTIC_management & -0.0405 & -0.0738 & 0.0133 & 0.0735 & 0.0275 \\
\hline & IUITC_advanced & -0.0394 & -0.0719 & 0.0130 & 0.0716 & 0.0268 \\
\hline \multirow{4}{*}{$\begin{array}{l}\text { Improved its } \\
\text { overall results }\end{array}$} & IA & -0.0033 & -0.0072 & -0.0012 & 0.0082 & 0.0035 \\
\hline & IUTIC_basic & -0.0471 & -0.1027 & -0.0171 & 0.1174 & 0.0496 \\
\hline & IUTIC_management & -0.0333 & -0.0726 & -0.0121 & 0.0829 & 0.0350 \\
\hline & IUITC_advanced & -0.0322 & -0.0701 & -0.0117 & 0.0801 & 0.0338 \\
\hline
\end{tabular}




\section{Discussion}

Having identified three groups of indicators for ICT development and implementation in companies (i.e. basic, management and advanced), our main result indicates that ICT intensity has a significant positive effect on the perception of overall corporate performance, in general, and on each of the different variables analysed related with corporate performance, in particular (i.e. differentiation, costs, new business opportunities, productivity and income). These findings are in keeping with the theoretical framework (e.g. Hollenstein, 2004, TorrentSellens \& Díaz-Chao, 2014, Venturi, 2015) as ICT adoption supposes a potential source of competitive advantages, either by enabling the company to stand out its competitors (based on product innovation, improving customer orientation, after-sales services, etc.) or by reducing costs or improving productivity.

Nevertheless, the contribution of each type of ICT is not uniform, and it is possible to see how the group of basic ICTs (computer equipment and mobile devices, e.g. PDAs or Smartphones) has the greatest impact on corporate performance. This is particularly noticeable in the ensuing effect on cost reduction and the exploitation of new business opportunities. Despite the fact that specialist literature describes the commoditization of this type of ICTs (Carr, 2003), which are necessary for the company but which do not have a positive impact on its performance, our results contradict these conclusions. Perhaps, as Niemi (2006) or Rohrbeck (2010) advise, the companies in the study have managed to integrate ICTs not only into their structures but also into their strategies, operational criteria, etc. We should also bear in mind that the Spanish corporate fabric comprises small- and medium-sized enterprises (SMEs), and so the size effect has also affected these results, as Hoque, Saif, AlBar, and Bao (2016) suggest in their study. This seems to be consistent with the findings of Ulmanis and Deninšs (2012), who indicated that small firms are more likely to adopt ICTs in response to new EU competitive threats. Future research should investigate whether there are significant differences in terms of company size, as Harindranath et al. (2008) or Burke (2010) have suggested.

Our results also suggest that sector attractiveness has a significant positive effect on corporate performance, although its predictive capacity is significantly lower than for the case of ICT intensity. This finding is consistent with that of Ulmanis and Deniňš (2012), who indicated that perception of competitive forces can increase the perception of benefits arising from ICT adoption. According to Porter (1980), the combined result of the five forces indicates sector attractiveness, which is why the more powerful the five forces are, the lower the possibility of obtaining high benefits, due to the greater competitive intensity. In very competitive contexts, where the need to find new alternative sources of competitive advantages is greater, companies have a more intensive use of ICTs in terms of number and sophistication, in order to gain in both internal and external effectiveness (Pontikakis et al., 2006). In line with Mehrtens et al. (2001), our results indicate the possible existence of an indirect effect of ICT adoption on corporate performance variables which focus on the company's external processes, such as the improvement in competence differentiation, the exploitation of new business opportunities and increase in sales income, according to industry attractiveness. Further research is required to investigate in greater detail the moderating effects that this 
industry attractiveness has on the relationship between ICT intensity of use and corporate performance as highlighted by Xue et al. (2012).

By way of summary, this research supports the conclusion that ICT adoption can also be a differentiating factor by creating competitive advantages that improve a firm's competitiveness through income generation as a result of cost reduction or greater sales, for example, although there are many unknown factors that need to be addressed in this research context.

\section{Conclusions}

In this paper, we study the ICT adoption behaviour of Spanish SMEs and how ICT intensity of use and sector attractiveness affect the perceived usefulness of ICTs in improving different aspects of corporate performance. Although there is general consensus about the benefits of ICT incorporation in companies, its impact on corporate performance is unclear (e.g. Cardona, Kretschmer, \& Strobel, 2013; Ghobakhloo et al., 2011; Nguyen, 2009). Therefore, the study advances established ICT literature by providing empirical evidence that this relationship is both positive and significant. This study also enriches ICT literature by examining the relationship between sector attractiveness, defined in terms of competitive strengths, and the perceived usefulness of ICTs in improving corporate performance. This relationship is both positive and significant, although as mentioned earlier, future research should explore this relationship in greater depth and also how sector attractiveness might affect the relationship between ICT intensity of use and perceived corporate performance.

These findings should be viewed in the light of certain limitations. Firstly, the empirical study focuses on the analysis of listed firms in Spain alone. Future research might also focus on other national contexts in order to enable a comparison, in line with Hagsten and Kotnik (2017). A comparative analysis between two blocks could also be considered: one comprising the nations with high competitiveness against others with a low competitive level. Secondly, this study represents a first attempt to capture industry attractiveness in a single variable. However, Porter's original approach (1980) considered each force to be a construct with several items. In future research, it would be interesting to verify the multidimensionality of this construct. It would also be interesting to separately analyse the effects that cause each of the competitive forces that characterise a sector in the perceived usefulness of ICT in improving corporate performance. Thirdly, since only perceived performance measures were used in this study in future research other more objective ones could be used or a combination of these. In addition, the self-reported nature of the data may have resulted in an optimistic bias, making participants report higher performance of ICT. As Drew (2003) suggests, further future research should also analyse the industry effect to examine whether there are significant differences in ICT intensity of use between industries with different competitive levels in order to reinforce and complement the conclusions obtained in this study.

In terms of the implications of this study for practitioners, it is possible to draw one interesting conclusion: as an integral part of the company, ICTs exert a positive impact on corporate performance, particularly in very competitive environments. According to Bayo-Morionesa and Lera-López (2007), strategies, operational criteria and organizational formulas must be considered both collectively and comprehensively with the ICT-use strategy in order 
to achieve the desired effects. In this regard, managers must be completely involved in the ICT adoption and updating process and employees must be trained in ICT use and aware of the benefits that correct ICT use can provide both in improving their own personal performance (in terms of productivity) and in improving corporate performance. The difficulty lies in the constant and rapid evolution or innovation of ICT solutions applicable to the corporate environment. That is why the results observed here aim to provide a baseline for future studies into the effects of emerging ICTs.

\section{Acknowledgement}

We would like to thank to Dr. Rodrigo Lozano for helpful and constructive comments on an earlier draft.

\section{Funding}

This work was supported by the European Regional Development Fund (ERDF) and the University of Castilla-La Mancha (GI20163487).

\section{References}

Andersen, T. K. (2015). Employees' involuntary non-use of ICT influenced by power differences: a case study with the grounded theory approach. Interdisciplinary Journal of Information, Knowledge, and Management, 10, 117-143. https://doi.org/10.28945/2279

Arvanitis, S., \& Loukis, E. N. (2009). Information and communication technologies, human capital, workplace organization and labour productivity: a comparative study based on firm level data for Greece and Switzerland. Information Economics and Policy, 21(1), 43-61.

https://doi.org/10.1016/j.infoecopol.2008.09.002

Assael, H., \& Keon, J. (1982). Nonsampling vs. sampling errors in survey research. Journal of Marketing, 46, 114-123. https://doi.org/10.2307/3203346

Avgerou, C. (2010). Discourses of ICT and development. Information Technologies and International Development, 6(3), 1-18.

Badescua, M., \& Garcés-Ayerbe, C. (2009). The impact of information technologies on firm productivity: empirical evidence from Spain. Technovation, 29(2), 122-129.

https://doi.org/10.1016/j.technovation.2008.07.005

Barba-Sánchez, V., Martínez-Ruíz, M. P., \& Jiménez-Zarco, A. I. (2007). Drivers, benefits and challenges of ICT adoption by small and medium sized enterprises (SMEs): a literature review. Problems and Perspectives in Management, 5(1), 103-114.

Bayo-Morionesa, A., Billon, M., \& Lera-López, F. (2013). Perceived performance effects of ICT in manufacturing SMEs. Industrial Management y Data Systems, 113(1), 117-135.

https://doi.org/10.1108/02635571311289700

Bayo-Morionesa, A., \& Lera-López, F. (2007). A firm-level analysis of determinants of ICT adoption in Spain, Technovation, 27(6-7), 352-366. https://doi.org/10.1016/j.technovation.2007.01.003

Benitez-Amado, J., \& Walczuch, R. M. (2012). Information technology, the organizational capability of proactive corporate environmental strategy and firm performance: a resource-based analysis. European Journal of Information Systems, 21(6), 664-679. https://doi.org/10.1057/ejis.2012.14 
Benito-Hernández, S., Platero-Jaime, M., \& Rodríguez-Duarte, A. (2012). Determinants of innovation in Spanish microenterprises: the importance of internal factors. Universia Business Review, 33, 104-121.

Berraies, S., \& Chaher, M. (2014). Knowledge creation process and firms' innovation performance: mediating effect of organizational learning. International Journal Resource Studies, 4(1), 204-222. https://doi.org/10.5296/ijhrs.v4i1.5517

Bresnahan, T., \& Trajtenberg, M. (1995). General purpose technologies 'Engines of growth'?. Journal of Econometrics, 65(1), 83-108. https://doi.org/10.1016/0304-4076(94)01598-T

Brynjolfsson, E., \& Hitt, L. M. (2000). Beyond computation: information technology, organizational transformation and business performance. Journal of Economic Perspectives, 14(4), 23-48. https://doi.org/10.1257/jep.14.4.23

Burke, K. (2010). The impact of internet and ICT Use among SME agribusiness growers and producers. Journal of Small Business \& Entrepreneurship, 23(2), 173-194. https://doi.org/10.1080/08276331.2010.10593480

Cardona, M., Kretschmer, T., \& Strobel. T. (2013). ICT and productivity: conclusions from the empirical literature. Information Economics and Policy, 25, 109-125. https://doi.org/10.1016/j.infoecopol.2012.12.002

Carr, N. G. (2003). IT doesn't matter. Harvard Business Review, May, 41-49.

Ca'Zorzi, A. (2011). Adoption and use of information systems and technology in manufacturing small and medium-sized enterprises. European Journal of Information Systems, 12, 127-141.

Cohen, J. F., \& Olsen, K. (2015). Knowledge management capabilities and firm performance: a test of universalistic, contingency and complementarity perspectives. Expert Systems with Applications, 42(3), 1178-1188. https://doi.org/10.1016/j.eswa.2014.09.002

Covin, J. G., Prescott, J. E., \& Slevin, D. P. (1990). The effects of technological sophistication on strategic profiles, structure and firm performance. The Journal of Management Studies, 27(5), 485-510. https://doi.org/10.1111/j.1467-6486.1990.tb00258.x

Dalken, F. (2014). Are Porter's five competitive forces still applicable? A critical examination concerning the relevance for today's business. University of Twente, Netherlands.

Dankova, C. (2009). Main aspects of enterprise architecture concept. Economic Alternatives, 1, 102-114.

Delgado-Gómez, J. M., Ramírez, M., \& Espitia, M. A. (2004). Intangible resources as a key factor in the internationalization of Spanish firms. Journal of Economic Behavior \& Organization, 53(4), 477-494. https://doi.org/10.1016/j.jebo.2002.11.001

Dewett, T., \& Jones, G. R. (2001). The role of information technology in the organization: a review, model and assessment. Journal of Management, 27(3), 313-346.

https://doi.org/10.1177/014920630102700306

Díaz-Chao, A., Sainz-González, J., \& Torrent-Sellens, J. (2015). ICT, innovation, and firm productivity: new evidence from small local firms. Journal of Business Research, 68, 1439-1444. https://doi.org/10.1016/j.jbusres.2015.01.030

Dholakia, R. R.; Kshetri, N. 2004. Factors Affecting the Adoption of the Internet among SMEs, Small Business Economics, 23, 311-322. https://doi.org/10.1023/B:SBEJ.0000032036.90353.1f

Drew, S. (2003). Strategic uses of e-commerce by SMEs in the east of England. European Management Journal, 21(1), 79-88. https://doi.org/10.1016/S0263-2373(02)00148-2

European Commission. (2014). Commission Regulation (EU) No 651/2014 of 17 June 2014 declaring certain categories of aid compatible with the internal market in application of Articles 107 and 108 of the Treaty Text with EEA relevance. Official Journal of the European Union: L187/1-L187/78.

Fisher, J. (1992). Use of non-financial performance measures. Journal of Cost Management, (Spring), 31-38. 
Ghobakhloo, M., Sabouri, M. S., Hong, T. S., \& Zulkifli, N. (2011). Information technology adoption in small and medium-sized enterprises; an appraisal of two decades literature. Interdisciplinary Journal of Research in Business, 1(7), 53-80.

Gonzálvez-Gallego, N., Molina-Castillo, F. J., Soto-Acosta, P., Varajaoc, J., \& Trigod, A. (2015). Using integrated information systems in supply chain management. Enterprise Information Systems, 9(2), 210-232. https://doi.org/10.1080/17517575.2013.879209

Hagsten, E., \& Kotnik, P. (2017). ICT as facilitator of internationalisation in small- and medium-sized firms. Small Business Economics, 48(2), 431-446. https://doi.org/10.1007/s11187-016-9781-2

Hair, J. F. Jr., Anderson, R. E., Tatham, R. L., \& Black, W. C. (1998). Multivariate Data Analysis (5 ${ }^{\text {th }}$ ed.). Upper Saddle River, NJ: Prentice Hall.

Harris, R. W. (2016). How ICT4D research fails the poor. Information Technology for Development, 22(1), 177-192. https://doi.org/10.1080/02681102.2015.1018115

Harindranath, G., Dyerson, R., \& Barnes, D. (2008). ICT Adoption and use in UK SMEs: a failure of initiatives?. The Electronic Journal Information Systems Evaluation, 11(2), 91-96.

Ho, P. H. K. (2016). Analysis of competitive environments, business strategies, and performance in Hong Kong's construction industry. Journal of Management in Engineering, 32(2). Retrieved from https://ascelibrary.org/doi/10.1061/\%28ASCE\%29ME.1943-5479.0000399

Hoque, M. R., Saif, A. N. M., AlBar, A. M., \& Bao, Y. (2016). Adoption of information and communication technology for development: a case study of small and medium enterprises in Bangladesh. Information Development, 32(4), 986-1000. https://doi.org/10.1177/0266666915578202

Hollenstein, H. (2004). Determinants of the adoption of Information and Communication Technologies (ICT): an empirical analysis based on firm-level data for the Swiss business sector. Structural Change and Economic Dynamics, 15, 315-342. https://doi.org/10.1016/j.strueco.2004.01.003

INE. (2015). Central Company Directory (DIRCE) of Spanish National Institute of Statistics (INE). Retrieved from http://www.ine.es/jaxi/menu.do?type=pcaxis\&path=/t37/p201/\&file=inebase

Liu, Y., \& Ravichandran, T. (2008). A comprehensive investigation on the relationship between information technology investments and firm diversification. Information Technology and Management, 9(3), 169-180. https://doi.org/10.1007/s10799-008-0042-1

López Sánchez, J. I., Minguela, B., Rodríguez, A., \& Sandulli, F. (2006). Is the internet productive? A firm-level analysis. Technovation, 26(7), 821-826. https://doi.org/10.1016/j.technovation.2005.03.002

Mačiulytė-Šniukienè, A., \& Gaile-Sarkane, E. (2014). Impact of information and telecommunication technologies development on labour productivity. Procedia-Social and Behavioral Sciences, 110, 1271-1282. https://doi.org/10.1016/j.sbspro.2013.12.974

Malone, T. S., Yates, J., \& Benjamin, R. I. (1987). Electronic markets and electronic hierarchies. Communications of the ACM, 30(6), 484-497. https://doi.org/10.1145/214762.214766

Marrano, M. G., Haskel, J., \& Wallis, G. (2009). What happened to the knowledge economy? ICT, intangible investment, and Britain's productivity. Review of Income and Wealth, 55(3), 686-716. https://doi.org/10.1111/j.1475-4991.2009.00344.x

Marx, Th. G. (2017). Impacts of industry attractiveness and competitive position on leadership. Management and Organizational Studies, 4(3), 1-13. https://doi.org/10.5430/mos.v4n3p1

Mehrtens, J., Cragg, P. B., \& Mills, A. M. (2001). A model of Internet adoption by SMEs. Information and Management, 39(3), 165-176. https://doi.org/10.1016/S0378-7206(01)00086-6

Mercader, J., Merono, A. L., \& Sabater, R. (2006). Information technology and learning: their relationship and impact on organisational performance in small businesses. International Journal of Information Management, 26(1), 16-29. https://doi.org/10.1016/j.ijinfomgt.2005.10.003

Morikawa, M. (2004). Information technology and the performance of Japanese SMEs. Small Business Economics, 23(3), 171-177. https://doi.org/10.1023/B:SBEJ.0000032023.11566.4b 
Molla, A., \& Licker, P. (2005). Perceived e-Readiness factor in e-Commerce adoption: an empirical investigation in a developing country. International Journal of Electronic Commerce, 10(1), 83-110.

Nguyen, T. U. H. (2009). Information technology adoption in SMEs: an integrated framework. International Journal of Entrepreneurial Behaviour and Research, 15(2), 162-186. https://doi.org/10.1108/13552550910944566

Niemi, E. (2006). Enterprise architecture benefits: perceptions from literature and practice. Internet \& Information Systems in the Digital Age: Challenges and Solutions, 24, 161-168.

Norusis, M. (2005). Ordinal regression. In M. Norusis. SPSS 13.0 Advanced Statistical Procedures Companion (pp. 69-89). Upper Saddle River, NJ: Prentice Hall.

Pantea, S., Sabadash, A., \& Biagi, F. (2017). Are ICT displacing workers in the short run? Evidence from seven European countries. Information Economics and Policy, 39, 36-44. https://doi.org/10.1016/j.infoecopol.2017.03.002

Pavic, S., Koh, S. C. L., Simpson, M., \& Padmore, J. (2007). Could e-business create a competitive advantage in UK SMEs?. Benchmarking, 14(3), 320-351. https://doi.org/10.1108/14635770710753112

Pla-Barber, J. (2000). The internalization of foreign distribution and production activities: new empirical evidence from Spain. International Business Review, 10, 455-474.

https://doi.org/10.1016/S0969-5931(01)00026-9

Platero-Jaime, M., Benito-Hernández, S., \& Rodríguez-Duarte, A. (2017). The moderator effect of training in the adoption of ICT in microenterprises. Cuadernos de Gestión, 17(2), 87-108.

https://doi.org/10.5295/cdg.150539mp

Pontikakis, D., Lin, Y., \& Demirbas, D. (2006). History matters in Greece: the adoption of Internetenabled computers by small and medium sized enterprise. Information Economics and Policy, 18, 332-358. https://doi.org/10.1016/j.infoecopol.2006.03.004

Porter, M. (1980). Competitive strategy: techniques for analysing industries and competitors. New York: Free Press.

Porter, M. E. (1998). Competitive advantage: creating and sustaining superior performance ( $2^{\text {nd }}$ ed.). New York: Free Press. https://doi.org/10.1007/978-1-349-14865-3

Porter, M. E., \& Millar V. E. (1985). How information gives you competitive advantage. Harvard Business Review, 63(4), 149-158.

Ravichandran, Th. (2005). Effect of information systems, resources and capabilities on firm performance: a resource based perspective. Journal of Management Information Systems, 21(4), 237-276. https://doi.org/10.1080/07421222.2005.11045820

Roach, S. S. (1991). Services under Siege: the restructuring imperative. Harvard Business Review, 39(2), 82-92.

Rohrbeck, R. (2010). Harnessing a network of experts for competitive advantage, technology scouting in the ICT industry. R\&D Management, 40(2), 169-180. https://doi.org/10.1111/j.1467-9310.2010.00601.x

Schmalensee, R. (1989). Inter-industry studies of structure and performance. In R. Schmalensee \& R. Willig (Eds.), Handbook of Industrial Organization (pp. 951-1009). Amsterdam: North-Holland publishing.

Senarathne-Tennakoon, K. L. U., da Silveira, G. J. C., \& Taras, D. G. (2013). Drivers of context-specific ICT use across work and nonwork domains: a boundary theory perspective. Information and Organization, 23(2), 107-128. https://doi.org/10.1016/j.infoandorg.2013.03.002

Spanos, Y. E., \& Lioukas, S. (2001). An examination of the causal logic of rent generation: contrasting Porter's competitive strategy framework and the resource-based perspective. Strategic Management Journal, 22(10), 907-934. https://doi.org/10.1002/smj.174

Stirbu, O. A., Ceptureanu, E. G., \& Ceptureanu, S. I. (2015). Theoretical approach regarding the competitiveness of SMEs. International Journal of Advanced Research, 3(6), 1057-1063. 
Strobel, T. (2014). Directed technological change, skill complementarities and sectoral productivity growth: evidence from industrialized countries during the new economy. Journal of Productivity Analysis, 42(3), 255-275. https://doi.org/10.1007/s11123-014-0405-Z

Torrent-Sellens, J., \& Díaz-Chao, A. (2014). ICT uses, innovation and SMEs productivity: modelling direct and indirect effects in small local firms. Internet Interdisciplinary Institute Working Paper Series, 14-001.

Tvrdíkováa, M. (2016). Increasing the business potential of companies by ensuring continuity of the development of their information systems by current information technologies. Journal of Business Economics and Management, 17(3), 475-489. https://doi.org/10.3846/16111699.2013.839475

Ulmanis, J., \& Deniņš, A. (2012). A management model of ICT adoption in Latvia. Procedia - Social and Behavioral Sciences, 41, 251-264. https://doi.org/10.1016/j.sbspro.2012.04.029

Venturi, F. (2015). The modern drivers of productivity. Research Policy, 44, 357-369. https://doi.org/10.1016/j.respol.2014.10.011

Wai-Sum, S., \& Bao, Q. (2008). Network strategies of small Chinese hightechnology firms: a qualitative study. Journal of Product Innovation Management, 25(1), 79-102.

Xue, L., Ray, G., \& Sambamurthy, V. (2012). Efficiency or innovation: how do industry environments moderate the effects of firms' it asset portfolios?. MIS Quarterly, 36(2), 509-528.

\section{APPENDIX}

Descriptive statistics

\begin{tabular}{|l|c|c|}
\hline & Mean & S.D. \\
\hline PUICT competiveness & 2.855 & 1.155 \\
\hline PUICT reducing business costs & 2.863 & 1.145 \\
\hline PUICT taking advantage of business opportunities & 3.055 & 1.208 \\
\hline PUICT corporate productivity & 3.026 & 1.150 \\
\hline PUICT increasing sales & 2.920 & 1.122 \\
\hline PUICT overall corporate performance & 3.082 & 1.113 \\
\hline IA & 16.216 & 3.079 \\
\hline
\end{tabular}

Notes: PUICT: Perceived usefulness of ICT; IA: Entrepreneur's perception of industry attractiveness. Source: own compilation. 